\title{
Adolescent idiopathic scoliosis: current perspectives
}

This article was published in the following Dove Press journal:

Orthopedic Research and Reviews

6 January 2014

Number of times this article has been viewed

\section{Firoz Miyanji}

British Columbia Children's Hospital, Vancouver, BC, Canada

Correspondence: Firoz Miyanji British Columbia Children's Hospital, 4480 Oak St - A234, Vancouver, BC V6H 3V4, Canada

Tel + I 604875265 |

Fax + I 6048752275

Email fmiyanji@cw.bc.ca
Abstract: Adolescent idiopathic scoliosis (AIS) remains a common and potentially severe musculoskeletal disorder. Although its etiology is largely unknown, ongoing research endeavors continue to improve our understanding of its potential origin and its natural history. Advances in understanding its true three-dimensional nature have sought to improve classification and management strategies. This review will attempt to highlight and give an overview of the current concepts in adolescent idiopathic scoliosis.

Keywords: AIS, current, natural history, management strategies

\section{Etiology}

The current consensus on adolescent idiopathic scoliosis (AIS) maintains that it has a multifactorial etiology with genetic predisposing factors. Numerous theories continue to span a broad range of plausibilities in the etiopathogenesis of AIS. To date, the literature has focused on genetic links, metabolic and hormonal disturbances, growth asymmetry, central nervous system alterations, and mechanical and connective tissue abnormalities.

Multiple reports support the role of inheritance in the development of AIS. Population studies of index patients and their families have reported on an overall risk of inheritance. They suggest an $11 \%$ risk to first-degree relatives, $2.4 \%$ risk to second-degree relatives, and $1.4 \%$ to third-degree relations. ${ }^{1} \mathrm{~A}$ meta-analysis of different twin studies found a $73 \%$ concordance rate in monozygotic twins compared to $36 \%$ in dizygotic twins. ${ }^{2,3}$ A number of different gene loci linked to AIS have been revealed with advances in gene-analysis techniques. ${ }^{4}$ Miller $^{5}$ suggested candidate regions on chromosomes $6,9,16$, and 17 , and more recently a genetic linkage of chromosome 18 was also found. ${ }^{6}$ A clear mode of inheritance of AIS has been confirmed, and reports on autosomal dominant, X-linked, and multifactorial inheritance patterns have all been reported.

More recently, the development of genome-wide association studies (GWAS) have provided a more comprehensive picture on the possible genes involved in the potential etiology and pathogenesis of AIS. Candidate susceptible genes have been identified in GWAS of case-control cohorts in AIS. Ward et al ${ }^{7}$ used GWAS with 1.8 million genetic markers to compare 1,200 AIS patients with 1,500 controls. They refined their 202 markers down to 30 that were claimed to be most useful prognostic markers for curve progression. They calculated a "risk of progression" score from DNA analysis sampled from saliva, and although potentially promising, these findings require further 
investigation, given the apparent genetic heterogeneity of the disease. ${ }^{8}$ Although this type of analysis does not provide pure etiological evidence, the recognition of prognostic factors for AIS progression would be very relevant in daily practice.

The development of a scoliotic deformity has been consistently reported in pinealectomized chicken, suggesting melatonin deficiency as a possible cause. Others have noted mean blood melatonin concentrations to be significantly lower in animals with scoliosis compared to those without. ${ }^{9}$ A study involving 30 AIS patients with progressive scoliosis found a $35 \%$ decrease in melatonin throughout the night compared to controls. ${ }^{10}$ Despite these earlier studies suggesting that a defect in melatonin synthesis or metabolism might contribute to scoliosis, others have not been able to replicate these results. A pinealectomy model using nonhuman primates did not produce scoliosis, despite melatonin suppression. ${ }^{11}$ Melatonin-level measurements have been equally controversial, with most studies showing no abnormalities in melatonin levels in patients with AIS. ${ }^{12}$ In addition, no mutations have been identified in any of the known melatonin-related receptors in AIS patients. ${ }^{13}$

Melatonin signaling has been shown to be impaired in osteoblasts of patients with AIS. ${ }^{14}$ This finding has led to the development and validation of a clinical blood test that may serve as a presymptomatic screening test to identify asymptomatic children at risk of developing scoliosis. ${ }^{15,16}$ This suggests that melatonin metabolism may be more important in curve progression in AIS rather than a primary etiological factor.

Calmodulin has also been previously implicated in the etiology of scoliosis. Increased levels in platelets have been shown to be associated with progression of AIS. ${ }^{17}$ Cohen et al ${ }^{18}$ suggested that platelet calmodulin levels may be a better predictor for curve progression after finding a 2.5- to 3-fold increase in the activity of calmodulin in platelets of patients with AIS. Lowe et al also showed a direct relationship between higher platelet calmodulin levels and curve progression. ${ }^{19}$

Overall, there appear to be abnormalities in a number of hormones and signaling pathways; however, their precise roles in the pathogenesis of AIS remain inconclusive. There continue to be efforts in identifying yet other biological markers for the early prediction and prognostication of AIS. ${ }^{7,15,16,20}$

Growth asymmetry has been put forward as an etiology of AIS. Roaf ${ }^{21}$ originally described a vicious cycle of asymmetric loading from scoliosis, resulting in disproportionate rates of growth between the concave and convex sides of the spine (the Hueter-Volkmann principle). More recently, it has been suggested that the disproportionate growth occurs between the anterior and posterior vertebral columns. The relative anterior spinal overgrowth results in buckling of the spine, and causes the coronal curvature and the vertebral rotation. ${ }^{22,33}$ The thoracic hypokyphosis that frequently occurs in AIS is a factor supporting this theory. ${ }^{24-26}$ The inhibition of posterior growth may be tethered by muscle, ligament, or the spinal cord. The effects of these biomechanical factors may contribute to the progression and/or the pathogenesis of the spinal deformity, and alone are not considered primary etiological factors.

A number of previous experimental studies have highlighted abnormalities of the central nervous system that can produce scoliosis. Pinealectomy or destruction of the brain stem or hypothalamus, damage to the dorsal column of the spinal cord, and experimentally induced syringomyelia have all resulted in scoliosis. ${ }^{27,28}$ Syringomyelia associated with a Chiari malformation has a substantially high prevalence in AIS. ${ }^{29,30}$ In addition, the higher incidence of scoliosis in patients with Friedreich's ataxia, tethered cord, and myelomeningocele suggests that central nervous system abnormalities are contributing factors. Asymptomatic spinal cord tethering, as noted on magnetic resonance imaging, has been postulated as a cause of AIS. Also, abnormalities in vestibular function, postural control, and proprioception function have all been found in patients with AIS. ${ }^{31}$ Whether these findings are primary contributors in spinal curve development or are secondary to the spinal deformity remains unknown.

Altered electromyographic activity of the paraspinal muscles, ${ }^{32}$ biomechanical disk alterations, ${ }^{33,34}$ ligament laxity, and osteoporosis have all been reported as factors associated with AIS. To date, in spite of all the continued research efforts, no single causative factor of AIS has been conclusively established. Differentiating an observation as being a primary etiological factor or secondary to the spinal deformity remains a challenge.

Currently, AIS is considered a complex genetic disorder with an unclear pattern of inheritance and a significant degree of heterogeneity. It is influenced by multiple extrinsic factors that can broadly be divided into predisposing, initiating, and contributing to its pathogenesis.

\section{Natural history and prognostic testing}

Epidemiological studies on scoliosis are cross-sectional and generally focus on adolescents, hence these studies only define the prevalence of scoliosis for this age group. 
Approximately $2 \%-3 \%$ of adolescents have idiopathic scoliosis defined as a Cobb angle of greater than $10^{\circ}$. Curves of this magnitude have an equal prevalence in both boys and girls. The prevalence of curves greater than $30^{\circ}$ decreases to $0.2 \%$, and for curves greater than $40^{\circ}$ it is less than $0.1 \%$. The ratio of girls to boys, however, increases dramatically as the curves get bigger, with approximately a 10:1 ratio for curves greater than $30^{\circ}$. In general, less than $10 \%$ of positively screened children will require treatment. ${ }^{35,36}$

The progression of scoliosis is related primarily to skeletal maturity, curve magnitude, curve location, and sex. Assessment of skeletal maturation landmarks remains Tanner stage, menarche, Risser grade, lateral humeral condylar closure, and triradiate-cartilage closure. Challenges with these traditional markers are that they do not correlate exactly with the peak height velocity and occur either before (triradiate closure) or after (Risser 1, menarche) the onset of peak height velocity, and hence maximum curve progression of the scoliosis. More recently, Sanders et al ${ }^{37}$ introduced a simplified Tanner-Whitehouse III skeletal maturity assessment that more closely correlated with the onset of peak height velocity compared to the earlier indicators. Those at greatest risk of progression remain the young, skeletally immature female with a large curve. ${ }^{38}$

The most frequently noted long-term sequelae of untreated AIS are curve progression, back pain, cardiopulmonary compromise, and psychosocial concerns. Curves less than $30^{\circ}$ at skeletal maturity tend not to progress. Thoracic curves of $50^{\circ}-75^{\circ}$ are felt to continue to progress approximately $0.75^{\circ}-1^{\circ}$ per year. Lumbar curves greater than $30^{\circ}$ tend to progress, and more so if a significant rotational abnormality exists. ${ }^{39}$ Reports of back pain in patients with untreated AIS are variable. Ascani et $\mathrm{al}^{40}$ noted the frequency of back pain in adults with AIS to be similar to that of the general population, while others showed that chronic pain was more frequent and of greater intensity and duration in scoliotics than in the general population..$^{41,42}$ Although it is now well recognized that mortality rates for individuals with AIS are comparable with those of the general population, curve magnitude has been found to be negatively correlated with pulmonary function. Larger curves with a thoracic apex have been associated with reduced vital capacity and more frequent shortness of breath, but rarely severe cardiopulmonary compromise ${ }^{41,43-47}$ Despite these findings, a pulmonary function deficit did not always lead to a functional deficit in daily activities. ${ }^{48}$

The risk of progression in AIS remains the primary clinical concern. To date, previous population-based studies have given at best a general guideline for those patients at greatest risk for progression. Identification of specific prognostic factors that may predict the risk of progression in individual patients and curve types has been the focus in recent years by some groups. ${ }^{16,49,50} \mathrm{An}$ attempt at identifying genetic and biological prognostic markers, either through DNA analysis sampled from saliva or functional blood testing, may provide an individual risk assessment of curve progression. This could potentially reduce repetitive radiation exposure, unnecessary brace treatments, and cost of care related to follow-up, particularly in low-risk patients. This area of research still requires clinical validation.

\section{Classification}

Classification systems ideally are a means to assess a clinical entity, guide treatment, and allow comparison of different treatment methods to optimize care. Based on the principle of selective fusion, King et $\mathrm{al}^{51}$ subdivided basic curve types to help facilitate the selection of the areas to be fused in AIS. Their description of the five curve types has remained the principal means of classifying thoracic AIS curves since the early 1980s. More recently, Lenke et al, ${ }^{52}$ noting some of the limitations of the King classification system, introduced a two-dimensional treatment-based system, which has been noted by several authors to be more reliable and reproducible than the King et al classification system. ${ }^{53-55}$

Lenke's new classification system consists of six curve types, a lumbar spine modifier, and a sagittal thoracic modifier (Figure 1). This triad system expanded the simple fivecurve King classification to yield 42 possible curve patterns. Despite its goal of being comprehensive, authors have reported on some of the limitations of the Lenke system. ${ }^{56}$ The lumbar modifier has been challenged by Miyanji et al, ${ }^{56}$ noting that the $\mathrm{A}$ and $\mathrm{B}$ modifiers in Lenke 1 curves did not describe two distinct curve types within the Lenke 1 group, but rather the tilt direction of the L4 vertebrae was more useful in distinguishing two truly different curve patterns within the Lenke 1A classification (Figure 2). Also, the classification system does not include any clinical information, such as shoulder-height differences, trunk balance, or degree of skeletal immaturity. These important parameters can affect treatment decisions.

Currently, the evaluation and potential classification of AIS using three-dimensional terminology and techniques is being developed. The Scoliosis Research Society has formulated a three-dimensional classification committee for this purpose. A new method, the da Vinci representation, was 


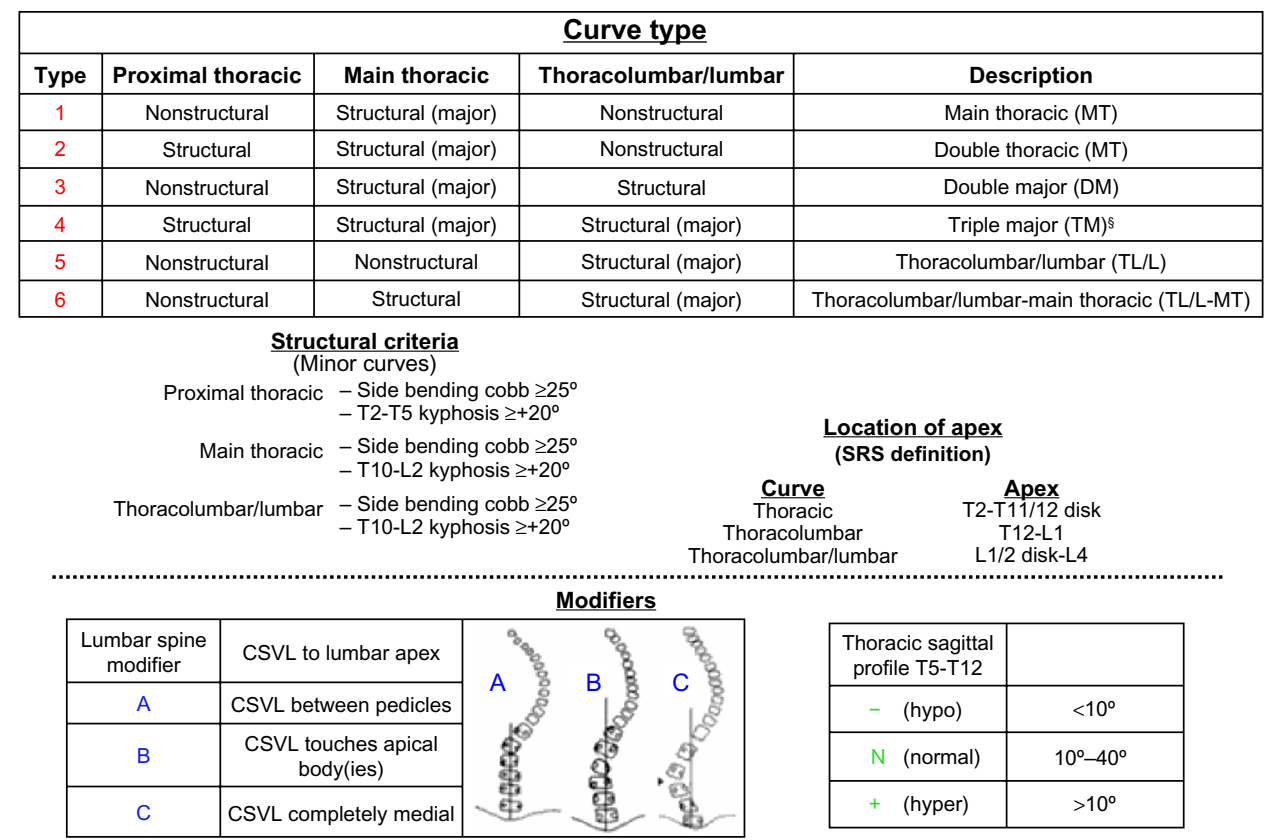

Curve type (1-6) + lumbar spine modifier $(A, B, C)+$ thoracic sagittal modifier $(-, N,+)$ Classification $(\mathrm{eg}, 1 \mathrm{~B}+)$ :

Figure I The Lenke classification system of adolescent idiopathic scoliosis.

Notes: Major refers to the largest cobb measurement, always structural. Minor refers to all other curves with structural criteria applied. $§$ Type 4 - MT or TL/L can be major curve. Copyright (c) 200I. Reproduced with permission from Journal of Bone and Joint Surgery, Inc. Lenke LG, Betz RR, Harms J, et al. Adolescent idiopathic scoliosis: a new classification to determine extent of spinal arthrodesis. J Bone Joint Surg Am. 200 I;83(8):1 I69-1 I81. ${ }^{52}$ http://jbjs.org/.

Abbreviation: CSVL, center sacral vertical line.

recently reported for describing top-down representation of the major curves onto a transverse axis. ${ }^{57}$ Each of the three regions of the spine - the proximal thoracic, main thoracic, and thoracolumbar/lumbar - are represented by a plane of maximal deformity representing the alterations in their three-

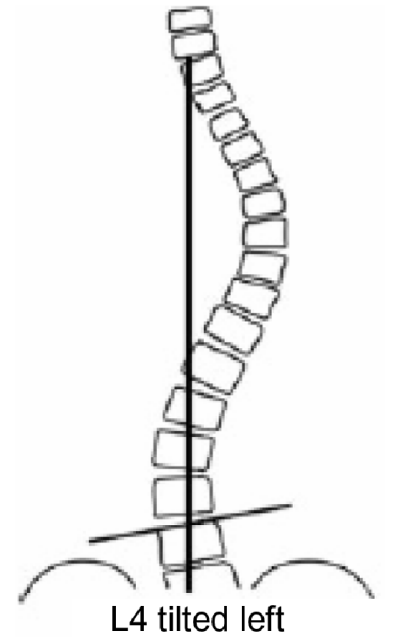

$(1 \mathrm{~A}-\mathrm{L})$

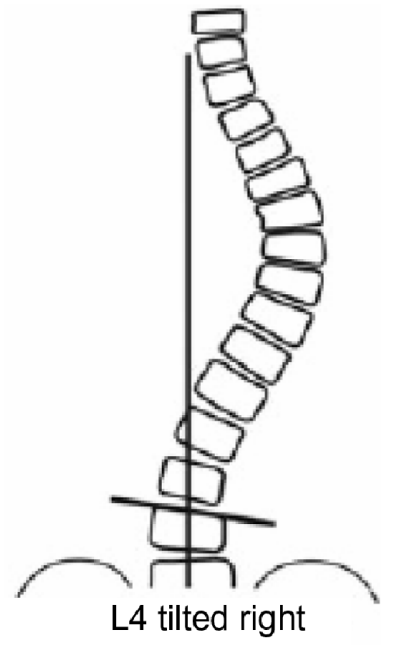

$(1 \mathrm{~A}-\mathrm{R})$
Figure 2 Determination of L4 tilt direction in Lenke IA curves.

Note: Adapted with permission form Lippincott Williams and Wilkins/Wolters Kluwer Health: Spine. Miyanji F, Pawelek JB, Van Valin SE, Upasani VV, Newton PO. Is the lumbar modifier useful in surgical decision making? Spine (Phila Pa 1976). 2008;33(23):2545-255I. ${ }^{56}$ Copyright 2008. dimensional alignment. This da Vinci representation, however, has yet to be validated as useful in clinical practice.

\section{Management}

\section{Bracing}

Management of AIS involves observation, bracing, or surgical intervention. Despite bracing being advocated for skeletally immature patients (Risser 0-2) with curves between $25^{\circ}$ and $45^{\circ}, 58,59$ its effectiveness has been challenged by numerous authors. ${ }^{60-63}$ Previous studies focusing on brace treatment for AIS lack uniformity in inclusion criteria for bracing, compliance measures, surgical indications, and defining a common metric for success or failure of orthotic treatment. ${ }^{64,65}$ In fact, Richards et al ${ }^{65}$ attempted to establish consistent parameters for bracing studies so that valid and reliable comparisons could be made.

The most recent systematic reviews on the efficacy of bracing found methodologically poor-quality studies with low levels of evidence that were inconsistent or inconclusive in recommending bracing over observation for AIS. ${ }^{64,66,67}$ Dolan and Weinstein's ${ }^{64}$ evidence-based review critically analyzed the literature to determine a pooled estimate of the prevalence of surgery after observation and after brace treatment in AIS. The review included a total of 18 studies 
all graded level III or IV. The authors concluded that the pooled surgical rate was $23 \%$ after bracing compared to $22 \%$ after observation alone, suggesting that according to previous published data, there was no clear advantage of recommending bracing over observation to prevent surgery for AIS. ${ }^{64}$ Although a recent observational study ${ }^{68}$ noted a favorable dose-response relationship for compliance with brace wear, the authors used a surrogate outcome of curve progression of greater than $6^{\circ}$. Whether patients with a $6^{\circ}$ progression develop curves into a surgical range remains unclear.

Noting the limitations of the available literature regarding brace treatment in the setting of AIS, a prospective multicenter randomized controlled trial was initiated within North America: the Bracing in Adolescent Idiopathic Scoliosis Trial (BRAIST). ${ }^{69}$ This study, although attempting ultimately to randomize all patients into either a bracing arm or observation arm, was able to do so in 116 patients, and followed 126 patients in a preference cohort. The primary aim of the study was to determine the effectiveness of bracing in preventing curve progression to $50^{\circ}$ or more (a common indication for surgery) compared to observation. The trial concluded a $72 \%$ success rate after bracing compared to $48 \%$ after observation, and also noted a significant positive association between average hours of daily brace wear and the likelihood of treatment success. The BRAIST study found that bracing significantly reduces the progression of high-risk curves to the threshold for surgery; however, selecting patients at high risk for progression remains a challenge. The importance of identifying those at high risk may help in narrowing the current rather broad indications for bracing, so that unnecessary treatment for patients may be avoided. ${ }^{69}$

\section{Surgical treatment}

To date, surgical options and goals of surgery in AIS patients continue to be the same. In general, for skeletally immature patients in whom the curve reaches $40^{\circ}-50^{\circ}$ or skeletally mature patients with curves greater than $50^{\circ}$, surgery is indicated. These remain guidelines rather than absolute indications for surgery, and one should also consider clinical deformity, risk for progression, skeletal maturity, and curve pattern when deciding between operative and nonoperative treatment.

Open posterior instrumentation and fusion, open anterior instrumentation and fusion, and thoracoscopic techniques remain the gold standard in achieving a solid arthrodesis, obtaining a balanced three-dimensional correction of the spine, and limiting the extent of the fusion. With advances in modern posterior instrumentation systems, the use of pedicle screws in AIS deformities has now become routine. Pedicle screws have a number of reported advantages in AIS, including better deformity correction, less loss of correction, and decrease in number of levels being fused, ${ }^{70-72}$ and more importantly, the use of pedicle screws has reopened the debate of anterior versus posterior surgery in AIS.

The primary debate between anterior and posterior surgery for AIS is centered around concerns of crankshaft ${ }^{73}$ for the very young patient, the distal extent of the fusion, the ability to restore and maintain the sagittal plane, and when faced with severe, rigid deformities. Thoracoscopic techniques have reported more favorable postoperative lung function compared to open anterior thoracotomies ${ }^{74-76}$; however, perioperative morbidity with single-lung ventilation should not be overlooked. ${ }^{77,78}$ In addition, anterior thoracoscopic instrumented fusions rely on a single anterior rod, with most surgeons favoring a postoperative bracing protocol due to reports of significant pseudarthrosis rates in some studies. ${ }^{77-79}$

The crankshaft phenomenon has been historically reported with earlier Harrington, Cotrel-Dubousset, and Luque posterior systems. The risk of crankshaft with modern posterior pedicle-screw instrumentation has been increasingly challenged in recent years. ${ }^{80}$ Both clinical and animal studies found no occurrence of crankshaft in subjects once considered high risk (Risser 0, open triradiate cartilage) when segmental pedicle-screw constructs were used. ${ }^{81-85}$ Therefore, anterior surgery for the prevention of crankshaft has now become increasingly limited at most centers.

Previously thoracolumbar/lumbar (Lenke 5) curves treated anteriorly showed the advantage of saving an average of 1.2-3.5 levels compared to posterior constructs. ${ }^{86}$ Shufflebarger et al recently challenged anterior surgery in the setting of Lenke 5 curves, reporting an average $80 \%$ correction and normal lumbar lordosis with posterior pediclescrew constructs and Ponte releases. ${ }^{87}$ This study has now popularized posterior surgery for Lenke 5 curves, which historically were routinely treated by an anterior approach (Figure 3).

In a subsequent comparative study, Geck et $\mathrm{al}^{88}$ noted better curve correction, less loss of correction over time, and shorter hospital stay compared to an anterior approach for these curves. The extent of the arthrodesis, however, was not reported in the aforementioned studies. Others have also shown favorable operative times and length of hospital stay in patients treated with a posterior approach for Lenke 5 curves; however, all of these studies report that anterior surgery 
A
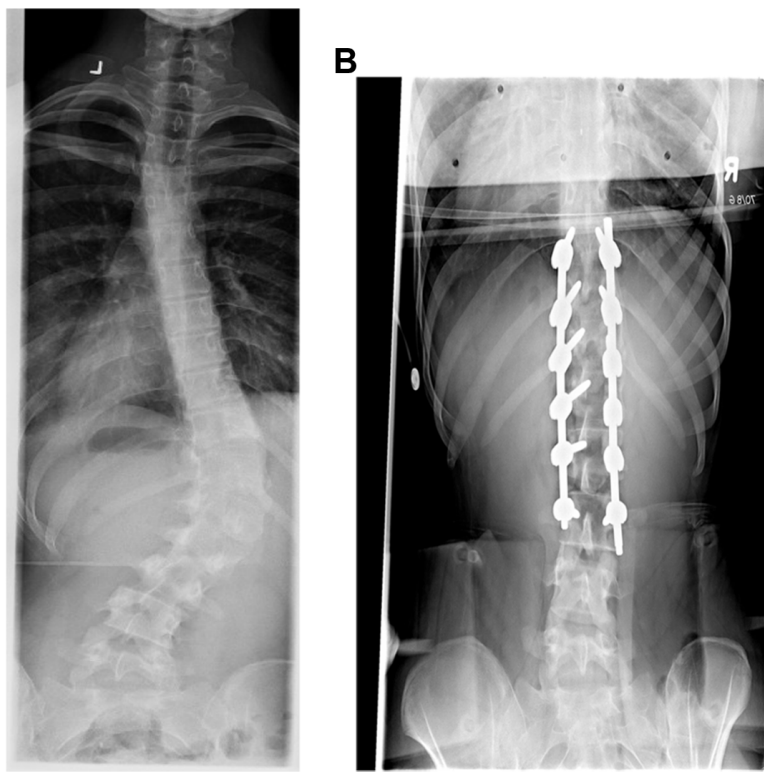

Figure 3 (A) Preoperative Lenke 5 curve in 16-year-old female. (B) Postoperative posterior-anterior $\mathrm{X}$-ray demonstrating surgical stabilization by posterior approach and Ponte releases.

resulted in shorter fusions, despite the use of pedicle-screw constructs in their posterior groups. ${ }^{89-92}$

Anterior release for large, stiff curves has generally been considered for curves $75^{\circ}$ or larger with decreased curve flexibility ( $\geq 50^{\circ}$ on side-bending films) ${ }^{93}$ Others have suggested an anterior release for curves of $60^{\circ}, 70^{\circ}$, or $100^{\circ}$, regardless of flexibility. ${ }^{94}$ The literature to date has only roughly estimated the improvement offered by an anterior release, with very limited data assessing the results after an anterior release in AIS. Reports of "little effect" on flexibility, 39\%-54\% improvement of spinal flexibility, and a mean $6 \%$ flexibility change or $5.5^{\circ}$ improvement in the Cobb angle have all been reported..$^{95-97}$ In more recent years, however, proponents of posterior pedicle-screw constructs have challenged the role of anterior release in the setting of large, stiff curves. Suk et $\mathrm{al}^{98}$ reported an average $65 \%$ correction of curves $\geq 70^{\circ}$ treated with posterior pedicle screws and no anterior release. Subsequent comparative studies of anterior release and posterior instrumentation with only posterior pedicle-screw constructs showed equivalent coronal plane correction in both groups, suggesting that anterior release for large, stiff curves is not warranted when a posterior pedicle-screw construct is used. ${ }^{99-101}$ It is worth noting that these studies were retrospective reviews, the comparative arm of anterior release with posterior instrumentation utilized hybrid/hook constructs, and not all used pedicle-screw instrumentation. Literature comparing anterior release with posterior pedicle-screw constructs and posterior pedicle-screw constructs alone in the
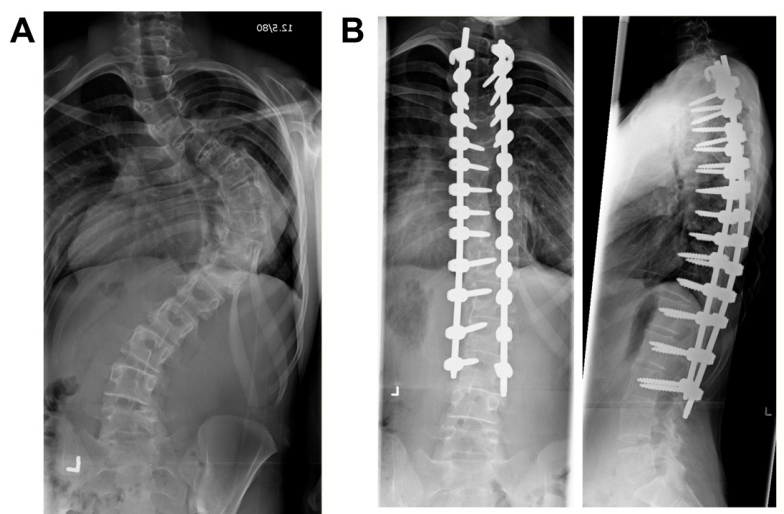

Figure 4 (A) Preoperative significant Lenke I curve in 14-year-old female. (B) Postoperative posterior-anterior and lateral X-rays demonstrating surgical stabilization by posterior approach only (no anterior release).

setting of large, stiff curves is lacking. Although the indication criteria for an anterior release when faced with large, stiff curves remains to be determined with current advances in posterior methods, certainly anterior procedures in this setting have been on the decline in most centers (Figure 4).

One of the primary advantages of anterior spinal instrumentation and fusion has been its ability to restore thoracic kyphosis in AIS. Historical data has supported this concept over posterior-only constructs. ${ }^{86,103-105}$ The most recent prospective multicenter comparison of posterior instrumentation and fusion, open anterior instrumentation and fusion, and
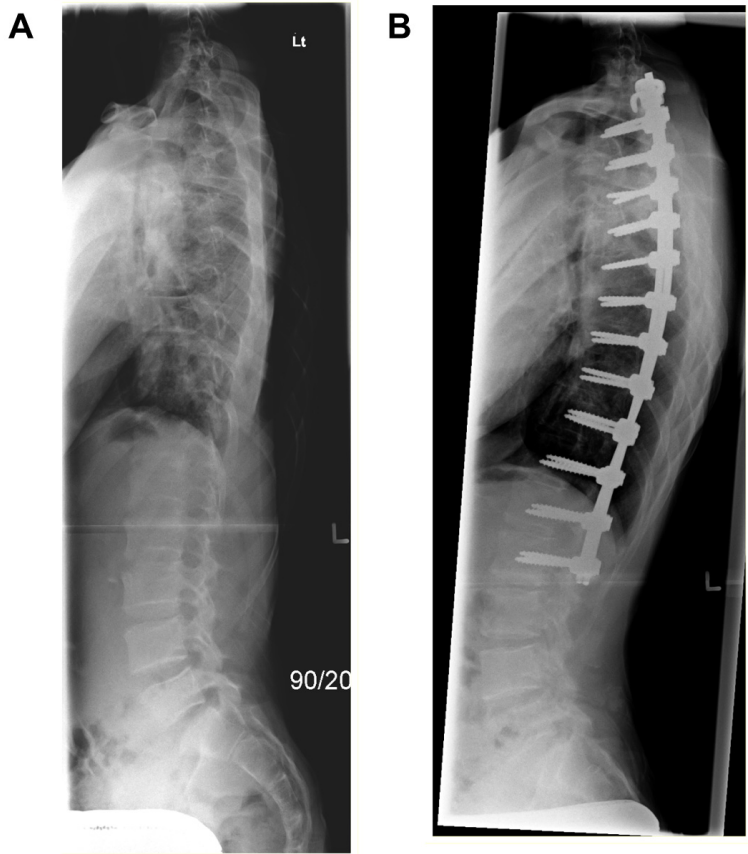

Figure 5 (A) Preoperative lateral X-ray demonstrating significant hypokyphosis in 15-year-old male. (B) Postoperative lateral X-ray following thoracoscopic anterior release and posterior instrumented fusion demonstrating restoration of thoracic kyphosis. 
thoracoscopic anterior spinal fusion found that the posterior spinal fusion group had more significant loss of thoracic kyphosis and lumbar lordosis compared to the anterior groups, thus reinforcing the kyphogenic advantage of anterior surgery over posterior procedures in AIS $^{106}$ (Figure 5).

The posterior approach to AIS has evolved to the routine use of thoracic pedicle screws. In addition to the previously noted advantages, other correction maneuvers now offered by screw-rod constructs specifically aimed at improving the axial plane deformity have also been recently described. Lee et al ${ }^{107}$ popularized direct vertebral apical derotation, which allows for greater reduction in rib prominence than other posterior techniques, and has obviated the use of routine thoracoplasty in AIS surgery. Samdani et al ${ }^{108}$ recently showed, however, that direct vertebral apical derotation with thoracoplasty further improves rib-hump deformity, and therefore thoracoplasty should still be considered in certain patients.

In addition to posterior-system advances, more aggressive posterior surgical techniques have also gained popularity in recent years. The widespread use of either a Ponte release or posterior osteotomies with bilateral facet removal has been postulated to provide a more complete correction of the deformity in all three planes. Although data supporting these suggestions are lacking, some authors have noted in their small retrospective series that no significant improvement in coronal or sagittal plane correction was gained with the use of Ponte releases compared to routine facetectomies. ${ }^{109}$

Surgery for AIS has always been met with guarded enthusiasm, as deformity correction is obtained at the expense of an arthrodesis. Certainly, long-term concerns of spinal fusion have been postulated, specifically with respect to loss of motion and implications on adjacent segments either proximal or distal to the arthrodesis. Previous studies have stressed the importance of fusing as few lumbar segments as possible; however, the real significance of this remains controversial and has been more of a debate on where the fusion ends. Fusions above L3 do not appear to have a significant impact on disk health and/or degeneration. More recently, Marks et $\mathrm{al}^{110}$ reported on postoperative motion at a minimum 2-year follow-up on patients treated surgically for AIS. The authors did not find any significant difference in postoperative motion in forward flexion between fusions ending at different levels in the lumbar spine. They did, however, find a significant difference in lateral bending depending on the distal extent of the fusion. The study noted a significantly greater degree of motion in lateral bending at the distal unfused segments, with a more distal instrumented level. They postulated that this increase in motion in the unfused segmental levels as a function of the lowest instrumented vertebrae (ie, more motion in lateral bending with a more distal fusion) may be cause for concerns of subsequent disk degeneration.

\section{Future trends}

With improvements and advances in instrumentation technologies, a trend toward minimally invasive surgery (MIS) approaches has been considered by some in the surgical treatment of AIS. ${ }^{111,112}$ The rationale for MIS in the setting of AIS is to try and minimize the approach-related morbidity inherent in the current available surgical options. A recent prospective comparison of posterior MIS to standard open posterior techniques in the setting of AIS found near-equivalent coronal and sagittal curve correction between the two techniques. ${ }^{111}$ Advantages of MIS over open posterior procedures were a significant lower average blood loss and a decreased length of hospital stay. Certainly, longer-term follow-up studies are needed to demonstrate the true clinical benefits of MIS in the setting of adolescent deformity.

Although spinal arthrodesis remains the gold standard in the management of progressive AIS, concerns about the long-term effects of spinal fusion and decreased spinal mobility have led to the development of growth-modulation techniques that may allow correction of the deformity without fusion. ${ }^{113,114}$ Vertebral body stapling and anterior spinal tethering are currently being investigated as potential fusionless treatment methods to manage progressive curves. ${ }^{114,115}$ The goal of these treatments is to control the patient's remaining spinal growth to achieve curve correction by exploiting the Hueter-Volkmann principle. The convex growth plates are compressed under tension, inhibiting their growth, while the concave growth plates continue to grow, hence straightening the spine. These methods are currently in limited clinical use, and data regarding the effectiveness and longer-term risk of these techniques remain outstanding. ${ }^{116}$

\section{Conclusion}

AIS is a three-dimensional deformity of the spine. Although it remains the center of tremendous research efforts, many fundamental questions regarding this complex condition continue to challenge investigators. Efforts at understanding its etiopathogenesis, risk of progression, ideal classification schemes, and treatments are ongoing, with advances in recent years providing new insights into our current knowledge of this multifaceted disorder.

\section{Disclosure}

The author reports no conflicts of interest relevant to the production of this manuscript. Dr Miyanji receives research 
support directed to his institution from DePuy Synthes Spine and also has a consultancy agreement with DePuy Synthes Spine.

\section{References}

1. Riseborough FJ, Wynne-Davies R. A genetic survey of idiopathic scoliosis in Boston, Massachussets. J Bone Joint Surg Am . 1973;55(5): 974-982.

2. Andersen MO, Thomsen K, Kyvik KO. Adolescent idiopathic scoliosis in twins: a population-based survey. Spine (Phila Pa 1976). 2007;32(8):927-930.

3. Kesling KL, Reinker KA. Scoliosis in twins: a meta-analysis of the literature and report of six cases. Spine (Phila Pa 1976). 1997;22(17):2009-2014.

4. Raggio CL, Giampietro PF, Dobrin S, et al. A novel locus for adolescent idiopathic scoliosis on chromosome 12p. J Orthop Res. 2009;27(10): 1366-1372.

5. Miller NH. Genetics of familial idiopathic scoliosis. Clin Orthop Relat Res. 2007;462:6-10.

6. Montanaro L, Parisini P, Greggi T, et al. Evidence of a linkage between matrilin-1 gene (MATN1) and idiopathic scoliosis. Scoliosis. 2006;1:21.

7. Ward K, Ogilvie J, Argyle V, et al. Polygenic inheritance of adolescent idiopathic scoliosis: a study of extended families in Utah. Am J Med Genet A. 2010;152A(5):1178-1188.

8. Sharma S, Gao X, Londono D, et al. Genome-wide association studies of adolescent idiopathic scoliosis suggest candidate susceptibility genes. Hum Mol Genet. 2011;20(7):1456-1466.

9. Machida M, Dubousset J, Imamura Y, Iwaya T, Yamada T, Kimura J. Role of melatonin deficiency in the development of scoliosis in pinealectomised chickens. J Bone Joint Surg Br. 1995;77(1): 134-138.

10. Machida M, Dubousset J, Imamura Y, Miyashita Y, Yamada T, Kimura J. Melatonin: a possible role in pathogenesis of adolescent idiopathic scoliosis. Spine (Phila Pa 1976). 1996;21(10):1147-1152.

11. Cheung KM, Wang T, Poon AM, et al. The effect of pinealectomy on scoliosis development in young nonhuman primates. Spine. 2005;30(18):2009-2013.

12. Bagnall KM, Raso VJ, Hill DL, et al. Melatonin levels in idiopathic scoliosis: diurnal and nocturnal serum melatonin levels in girls with adolescent idiopathic scoliosis. Spine (Phila Pa 1976). 1996;21(17):1974-1978.

13. Shyy W, Wang K, Gurnett C, et al. Evaluation of GPR50, hMel-1B, and ROR-alpha melatonin-related receptors and the etiology of adolescent idiopathic scoliosis. J Pediatr Orthop. 2010;30(6): 539-543.

14. Moreau A, Forget S, Azeddine B, et al. Melatonin signaling dysfunction in adolescent idiopathic scoliosis. Spine (Phila Pa 1976). 2004;29(16):1772-1781.

15. Moreau A, Turgeon I, Franco A, et al. Clinical validation of a functional blood test for adolescent idiopathic scoliosis. Poster presented at: Scoliosis Research Society 42nd Annual Meeting; September 5-8, 2007; Edinburgh, Scotland.

16. Moreau A, Akoume Ndong MY, Azeddine A, et al. [Molecular and genetic aspects of idiopathic scoliosis. Blood test for idiopathic scoliosis]. Orthopade. 2009;38(2):114-116, 118-121. German.

17. Kindsfater K, Lowe T, Lawellin D, Weinstein D, Akmakjian J. Levels of platelet calmodulin for the prediction of progression and severity of adolescent idiopathic scoliosis. J Bone Joint Surg Am. 1994;76(8):1186-1192.

18. Cohen DS, Solomons CS, Lowe TG. Altered platelet calmodulin activity in AIS. Orthop Trans. 1985;9:106.

19. Lowe T, Lawellin D, Smith D, et al. Platelet calmodulin levels in adolescent idiopathic scoliosis: do the levels correlate with curve progression and severity? Spine (Phila Pa 1976). 2002;27(7):768-775.
20. Akoume MY, Azeddine B, Turgeon I, et al. Cell-based screening test for idiopathic scoliosis using cellular dielectric spectroscopy. Spine (Phila Pa 1976). 2010;35(13): E601-E608.

21. Roaf R. The treatment of progressive scoliosis by unilateral growtharrest. J Bone Joint Surg Br. 1963;(45):637-651.

22. Guo X, Chau WW, Chan YL, Cheng JY. Relative anterior spinal overgrowth in adolescent idiopathic scoliosis. Results of disproportionate endochondral-membranous bone growth. J Bone Joint Surg Br. 2003;85(7):1026-1031.

23. Zhu F, Qiu Y, Yeung HY, Lee KM, Cheng JCY. Histomorphometric study of the spinal growth plates in idiopathic scoliosis and congenital scoliosis. Pediatr Int. 2006;48(6):591-598.

24. Porter RW. Can a short spinal cord produce scoliosis? Eur Spine J. 2001;10(1):2-9.

25. Porter RW. Idiopathic scoliosis: the relation between the vertebral canal and vertebral bodies. Spine (Phila Pa 1976). 2000;25(11): 1360-1366.

26. Porter RW. The pathogenesis of AIS: uncoupled neuro-osseous growth. Eur Spine J. 2001;10(6):473-481.

27. Barrios C, Tuñón MT, De Salis JA, Beguirstain JL, Cañadell J. Scoliosis induced by medullary damage: an experimental study in rabbits. Spine (Phila Pa 1976). 1987;12(5):433-439.

28. Machida M, Dubousset J, Imamura Y, Iwaya T, Yamada T, Kimura J. An experimental study in chickens for the pathogenesis of idiopathic scoliosis. Spine (Phila Pa 1976). 1993;18(12):1609-1615.

29. Arai S, Ohtsuka Y, Moriya H, Kitahara H, Minami S. Scoliosis associated with syringomyelia. Spine (Phila Pa 1976). 1993;18(12):1591-1592.

30. Isu T, Chono Y, Iwasaki Y, et al. Scoliosis associated with syringomyelia presenting in children. Childs Nerv Syst. 1992;8(2):97-100.

31. Beaulieu M, Toulotte C, Gatto L, et al. Postural imbalance in non-treated adolescent idiopathic scoliosis at different periods of progression. Eur Spine J. 2009;18(1):38-44.

32. Cheung J, Halbertsma JP, Veldhuizen AG, et al. A preliminary study on electromyographic analysis of the paraspinal musculature in idiopathic scoliosis. Eur Spine J. 2005;14(2):130-137.

33. Will RE, Stokes IA, Qiu X, Walker MR, Sanders JO. Cobb angle progression in adolescent scoliosis begins at the intervertebral disc. Spine (Phila Pa 1976). 2009;34(25):2782-2786.

34. Drevelle X, Lafon Y, Ebermeyer E, Courtois I, Dubousset J, Skalli W. Analysis of idiopathic scoliosis progression by using numerical simulation. Spine (Phila Pa 1976). 2010;35(10):E407-E412.

35. Kane WJ. Scoliosis prevalence: a call for a statement of terms. Clin Orthop. 1977;(126):43-46.

36. Robin GC. The Etiology of Idiopathic Scoliosis. Boca Raton (FL): CRC Press; 1990:43-60.

37. Sanders JO, Khoury JG, Kishan S, et al. Predicting scoliosis progression from skeletal maturity: a simplified classification during adolescence. J Bone Joint Surg Am. 2008;90(3):540-553.

38. Lonstein JE, Carlson JM. The prediction of curve progression in untreated idiopathic scoliosis during growth. J Bone Joint Surg Am. 1984;66(7):1061-1071.

39. Weinstein SL, Ponseti IV. Curve progression in idiopathic scoliosis. J Bone Joint Surg Am. 1983;65(4):447-455.

40. Ascani E, Bartolozzi P, Logroscino CA, et al. Natural history of untreated idiopathic scoliosis after skeletal maturity. Spine (Phila Pa 1976). 1986;11(8):784-789.

41. Weinstein SL, Dolan LA, Spratt KF, Peterson KK, Spoonamore MJ, Ponseti IV. Health and function of patients with untreated idiopathic scoliosis: a 50-year natural history study. JAMA. 2003;289(5): 559-567.

42. Weinstein SL, Zavala DC, Ponseti IV. Idiopathic scoliosis: long-term follow-up and prognosis in untreated patients. J Bone Joint Surg Am. 1981;63(1):702-712.

43. Barrios C, Pérez-Encinas C, Maruenda JI, Laguía M. Significant ventilatory functional restriction in adolescents with mild or moderate scoliosis during maximal exercise tolerance test. Spine (Phila Pa 1976). 2005;30(14):1610-1615. 
44. Pehrsson K, Bake B, Larsson S, Nachemson A. Lung function in adult idiopathic scoliosis: a 20 year follow up. Thorax. 1991;46(7):474-478.

45. Chong KC, Letts RM, Cumming GR. Influence of spinal curvature on exercise capacity. J Pediatr Orthop. 1981;1(3):251-254.

46. Kotani T, Minami S, Takahashi K, et al. An analysis of chest wall and diaphragm motions in patients with idiopathic scoliosis using dynamic breathing MRI. Spine (Phila Pa 1976). 2004;29(3):298-302.

47. Mankin HJ, Graham JJ, Schack J. Cardiopulmonary function in mild and moderate idiopathic scoliosis. J Bone and Joint Surg Am. 1964;46(1):53-62.

48. Newton PO, Faro FD, Gollogly S, Betz RR, Lenke LG, Lowe TG. Results of preoperative pulmonary function testing of adolescents with idiopathic scoliosis. A study of six hundred and thirty-one patients. J Bone Joint Surg Am. 2005;87(9):1937-1946.

49. Ogilvie JW. Update on prognostic genetic testing in adolescent idiopathic scoliosis (AIS). J Pediatr Orthop. 2011;31(Suppl 1): S46-S48.

50. Ward K, Ogilvie JW, Singleton MV, Chettier R, Engler G, Nelson LM. Validation of DNA-based prognostic testing to predict spinal curve progression in adolescent idiopathic scoliosis. Spine (Phila Pa 1976). 2010;35(25):E1455-E1464.

51. King HA, Moe JH, Bradford DS, Winter RB. The selection of fusion levels in thoracic idiopathic scoliosis. J Bone Joint Surg Am. 1983;65(9):1302-1313.

52. Lenke LG, Betz RR, Harms J, et al. Adolescent idiopathic scoliosis: a new classification to determine extent of spinal arthrodesis. $J$ Bone Joint Surg Am. 2001;83(8):1169-1181.

53. Richards BS, Sucato DJ, Konigsberg DE, Ouellet JA. Comparison of reliability between the Lenke and King classification systems for adolescent idiopathic scoliosis using radiographs that were not premeasured. Spine (Phila Pa 1976). 2003;28(11):1148-1156.

54. Niemeyer T, Wolf A, Kluba S, Halm HF, Dietz K, Kluba T. Interobserver and intraobserver agreement of Lenke and King classifications for idiopathic scoliosis and the influence of level of professional training. Spine (Phila Pa 1976). 2006;31(18):2103-2107.

55. Ogon $\mathrm{M}$, Giesinger $\mathrm{K}$, Behensky $\mathrm{H}$, et al. Interobserver and intraobserver reliability of Lenke's new scoliosis classification system. Spine (Phila Pa 1976). 2002;27(8):858-862.

56. Miyanji F, Pawelek JB, Van Valin SE, Upasani VV, Newton PO. Is the lumbar modifier useful in surgical decision making? Spine (Phila Pa 1976). 2008;33(23):2545-2551.

57. Sangole AP, Aubin CE, Labelle H, et al. Three-dimensional classification of thoracic scoliotic curves. Spine (Phila Pa 1976). 2009; 34(1):91-99.

58. Nachemson AL, Peterson LE. Effectiveness of treatment with a brace in girls who have adolescent idiopathic scoliosis: a prospective, controlled study based on data from the Brace Study of the Scoliosis Research Society. J Bone Joint Surg Am. 1995;77(6):815-822.

59. Danielsson AJ, Hasserius R, Ohlin A, Nachemson AL. A prospective study of brace treatment versus observation alone in adolescent scoliosis: a follow-up means of 16 years after maturity. Spine (Phila Pa 1976). 2007;32(20):2198-2207.

60. Focarile FA, Bonaldi A, Giarolo MA, Ferrari U, Zilioli E, Ottaviani C. Effectiveness of nonsurgical treatment for idiopathic scoliosis: overview of available evidence. Spine (Phila Pa 1976). 1991;16(4):395-401.

61. Goldberg CJ, Moore DP, Fogarty EE, Dowling FE. Adolescent idiopathic scoliosis: the effect of brace treatment on the incidence of surgery. Spine. 2001;26(1):42-47.

62. Noonan KJ, Weinstein SL, Jacobson WC, Dolan LA. Use of the Milwaukee brace for progressive idiopathic scoliosis. J Bone Joint Surg Am. 1996;78(4):557-567.

63. Emans JB. Brace treatment of idiopathic scoliosis: what makes sense in the new millennium. Spine (Phila Pa 1986). 2000;14(1):21-44

64. Dolan LA, Weinstein SL. Surgical rates after observation and bracing for adolescent idiopathic scoliosis: an evidence-based review. Spine (Phila Pa 1976). 2007;32(Suppl 19):S91-S100.
65. Richards BS, Bernstein RM, D’Amato CR, Thompson GH. Standardization of criteria for adolescent idiopathic brace studies: SRS Committee on Bracing and Nonoperative Management. Spine (Phila Pa 1976). 2005;30(18):2068-2075.

66. Negrini S, Minozzi S, Bettany-Saltikov J, et al. Braces for idiopathic scoliosis in adolescents. Spine (Phila Pa 1976). 2010;35(13): 1285-1293.

67. Davies E, Norvell D, Hermsmeyer J. Efficacy of bracing versus observation in the treatment of idiopathic scoliosis. Evid Based Spine Care J. 2011;2(2):25-34.

68. Katz DE, Herring JA, Browne RH, Kelly DM, Birch JG. Brace wear control of curve progression in adolescent idiopathic scoliosis. J Bone Joint Surg Am. 2010;92(6):1343-1352.

69. Weinstein SL, Dolan LA, Wright JG, Dobbs MB. Effects of bracing in adolescents with idiopathic scoliosis. $N$ Engl $\mathrm{J} \mathrm{Med}$. 2013;369(16):1512-1521

70. Asghar J, Samdani AF, Pahys JM, et al. Computed tomography evaluation of rotation correction in adolescent idiopathic scoliosis: a comparison of an all pedicle screw construct versus a hook-rod system. Spine (Phila Pa 1976). 2009;34(8):804-807.

71. Kim YJ, Lenke LG, Kim J, et al. Comparative analysis of pedicle screw versus hybrid instrumentation in posterior spinal fusion of adolescent idiopathic scoliosis. Spine (Phila Pa 1976). 2006;31(3):291-298.

72. Suk SI, Kim JH, Kim SS, Lim DJ. Pedicle screw instrumentation in adolescent idiopathic scoliosis (AIS). Eur Spine J. 2012;21(1):13-22.

73. Dubousset J, Herring JA, Shufflebarger H. The crankshaft phenomenon. J Pediatr Orthop. 1989;9(5):541-550.

74. Kishan S, Bastrom T, Betz RR, et al. Thoracoscopic scoliosis surgery affects pulmonary function less than thoracotomy at 2 years postsurgery. Spine (Phila Pa 1976). 2007;32(4):453-458.

75. Devinsky O, Morrell MJ, Vogt BA. Pulmonary function changes after various anterior approaches in the treatment of AIS. J Spinal Disord Tech. 1995;22(8):551-558.

76. Newton PO, Perry A, Bastrom TP, et al. Predictors of change in postoperative pulmonary function in adolescent idiopathic scoliosis: a prospective study of 254 patients. Spine (Phila Pa 1976). 2007;32(17): 1875-1882.

77. Reddi V, Clarke DV Jr, Arlet V. Anterior thoracoscopic instrumentation in adolescent idiopathic scoliosis: a systematic review. Spine (Phila Pa 1976). 2008;33(18):1986-1994.

78. Newton PO, Upasani VV, Lhamby J, Ugrinow VL, Pawelek JB, Bastrom TP. Surgical treatment of main thoracic scoliosis with thoracoscopic anterior instrumentation. A five-year follow-up study. $J$ Bone Joint Surg Am. 2008;90(10):2077-2089

79. Wong HK, Hee HT, Yu Z, Wong D. Results of thoracoscopic instrumented fusion versus conventional posterior instrumented fusion in adolescent idiopathic scoliosis undergoing selective thoracic fusion. Spine (Phila Pa 1976). 2004;29(18):2031-2038.

80. Tao F, Zhao Y, Wu Y, et al. The effect of differing spinal fusion instrumentation on the occurrence of postoperative crankshaft phenomenon in adolescent idiopathic scoliosis. J Spinal Disord Tech. 2010;23(8):e75-e80.

81. Sanders JO, Herring JA, Browne RH. Posterior arthrodesis and instrumentation in the immature (Risser-grade-0) spine in idiopathic scoliosis J Bone Joint Surg Am. 1995;77(1):39-45.

82. Hamill CL, Bridwell KH, Lenke LG, Chapman MP, Baldus C, Blanke K. Posterior arthrodesis in the skeletally immature patient. Assessing the risk for crankshaft: is an open triradiate cartilage the answer? Spine (Phila Pa 1976). 1997;22(12):1343-1351.

83. Sarlak AY, Atmaca H, Buluç L, Tosun B, Musaoğlu R. Juvenile idiopathic scoliosis treated with posterior arthrodesis and segmental pedicle screw instrumentation before the age of 9 years: a 5-year follow-up. Scoliosis. 2009;4:1

84. Kioschos HC, Asher MA, Lark RG, Harner EJ. Overpowering the crankshaft mechanism: the effect of posterior spinal fusion with and without stiff transpedicular fixation on anterior spinal column growth in immature canines. Spine (Phila Pa 1976). 1996;21(10):1168-1173. 
85. Burton DC, Asher MA, Lai SM. Scoliosis correction maintenance in skeletally immature patients with idiopathic scoliosis: is anterior fusion really necessary? Spine (Phila Pa 1976). 2000;25(1):61-68.

86. Betz RR, Harms J, Clements DH 3rd, et al. Comparison of anterior and posterior instrumentation for correction of adolescent thoracic idiopathic scoliosis. Spine (Phila Pa 1976). 1999;24(3):225-239.

87. Shufflebarger HL, Geck MJ, Clark CE. The posterior approach for lumbar and thoracolumbar adolescent idiopathic scoliosis: posterior shortening and pedicle screws. Spine (Phila Pa 1976). 2004;29(3): 269-276.

88. Geck MJ, Rinella A, Hawthorne D, et al. Comparison of surgical treatment in Lenke 5C adolescent idiopathic scoliosis: anterior dual rod versus posterior pedicle fixation surgery: a comparison of two practices. Spine (Phila Pa 1976). 2009;34(18):1942-1951.

89. Hee HT, Yu ZR, Wong HK. Comparison of segmental pedicle screw instrumentation versus anterior instrumentation in adolescent idiopathic thoracolumbar and lumbar scoliosis. Spine (Phila Pa 1976). 2007;32(14):1533-1542.

90. Burton DC, Asher MA, Lai SM. Patient-based outcomes analysis of patients with single torsion thoracolumbar-lumbar scoliosis treated with anterior or posterior instrumentation: an average 5-to 9-year follow-up study. Spine (Phila Pa 1976). 2002;27(21):2363-2367.

91. Li M, Ni J, Fang X, et al. Comparison of selective anterior versus posterior screw instrumentation in Lenke5C adolescent idiopathic scoliosis. Spine (Phila Pa 1976). 2009;34(11):1162-1166.

92. Wang Y, Fei Q, Qiu G, et al. Anterior spinal fusion versus posterior spinal fusion for moderate lumbar/thoracolumbar adolescent idiopathic scoliosis: a prospective study. Spine (Phila Pa 1976). 2008;33(20):2166-2172.

93. Lenke LG. Anterior endoscopic discectomy and fusion for adolescent idiopathic scoliosis. Spine (Phila Pa 1976). 2003;28(15):S36-S43.

94. Arlet V. Anterior thoracoscopic spine release in deformity surgery: a meta-analysis and review. Eur Spine J. 2000;9(1):S17-S23.

95. Wang YP, Xu HG, Qiu GX, Zhang JG, Yu B. [The effect of anterior spinal release on severe adolescent idiopathic scoliosis]. Zhonghua Wai Ke Za Zhi. 2004;42(2):77-80. Chinese.

96. Cheung KM, Lu DS, Zhang H, Luk KD. In-vivo demonstration of the effectiveness of thoracoscopic anterior release using the fulcrumbending radiograph: a report of five cases. Eur Spine J. 2006;15(5): 578-582.

97. Hempfing A, Ferraris L, Koller H, Rump J, Metz-Stavenhagen P. Is anterior release effective to increase flexibility in idiopathic thoracic scoliosis? Assessment by traction films. Eur Spine J. 2007;16(4): 515-520

98. Suk SI, Kim JH, Cho KJ, Kim SS, Lee JJ, Han YT. Is anterior release necessary in severe scoliosis treated by posterior segmental pedicle screw fixation? Eur Spine J. 2007;16(9):1359-1365.

99. Luhmann SJ, Lenke LG, Kim YJ, Bridwell KH, Schootman M. Thoracic adolescent idiopathic scoliosis curves between 70 degrees and 100 degrees: is anterior release necessary? Spine (Phila Pa 1976). 2005;30(18):2061-2067.

100. Dobbs MB, Lenke LG, Kim YJ, Luhmann SJ, Bridwell KH. Anterior/ posterior spinal instrumentation versus posterior instrumentation alone for the treatment of adolescent idiopathic scoliotic curves more than 90 degrees. Spine (Phila Pa 1976). 2006;31(20):2386-2391.
101. Zhang HQ, Gao QL, Ge L, et al. Strong halo-femoral traction with wide posterior spinal release and three dimensional spinal correction for the treatment of severe adolescent idiopathic scoliosis. Chin Med $J$ (Engl). 2012;125(7):1297-1302.

102. Kim YJ, Lenke LG, Bridwell KH, et al. Proximal junctional kyphosis in adolescent idiopathic scoliosis after 3 different types of posterior segmental spinal instrumentation and fusions: incidence and risk factor analysis of 410 cases. Spine (Phila Pa 1976). 2007;32(24): 2731-2738.

103. Rhee JM, Bridwell KH, Won DS, Lenke LG, Chotigavanichaya C, Hanson DS. Sagittal plane analysis of adolescent idiopathic scoliosis: the effect of anterior versus posterior instrumentation. Spine (Phila Pa 1976). 2002;27(21):2350-2356.

104. Tis JE, O'brien MF, Newton PO, et al. Adolescent idiopathic scoliosis treated with open instrumented anterior spinal fusion: five-year follow-up. Spine (Phila Pa 1976). 2010;35(1):64-70.

105. Sucato DJ, Agrawal S, O’Brien MF, Lowe TG, Richards SB, Lenke L. Restoration of thoracic kyphosis after operative treatment of adolescent idiopathic scoliosis: a multicenter comparison of three surgical approaches. Spine (Phila Pa 1976). 2008;33(24):2630-2636.

106. Newton PO, Marks MC, Bastrom TP, et al. Surgical treatment of Lenke 1 main thoracic idiopathic scoliosis: results of a prospective, multicenter study. Spine (Phila Pa 1976). 2013;38(4):328-338.

107. Lee SM, Suk SI, Chung ER. Direct vertebral rotation: a new technique of three-dimensional deformity correction with segmental pedicle screw fixation in adolescent idiopathic scoliosis. Spine (Phila Pa 1976). 2004;29(3):343-349.

108. Samdani AF, Hwang SW, Miyanji F, et al. Direct vertebral body derotation, thoracoplasty, or both: which is better with respect to inclinometer and Scoliosis Research Society-22 scores? Spine (Phila Pa 1976). 2012;37(14):E849-E853.

109. Halanski MA, Cassidy JA. Do mulitilevel ponte osteotomies in thoracic idiopathic scoliosis surgery improve curve correction and restore thoracic kyphosis? J Spinal Disord Tech. 2013;26(5):252-255.

110. Marks M, Newton PO, Petcharaporn M, et al. Postoperative segmental motion of the unfused spine distal to the fusion in 100 patients with adolescent idiopathic scoliosis. Spine (Phila Pa 1976). 2012;37(10):826-832.

111. Miyanji F, Samdani AF, Ghag A, Marks M, Newton PO. Minimally invasive surgery for AIS: an early prospective comparison with standard open posterior surgery. J Spine. 2013;2(4):S5-S001.

112. Samdani AF, Asghar J, Miyanji F, Haw J, Haddix K. Minimally invasive treatment of pediatric spinal deformity. Semin Spine Surg. 2011;23(1):72-75.

113. Newton PO, Fricka KB, Lee SS, Farnsworth CL, Cox TG, Mahar AT. Asymmetrical flexible tethering of spine growth in an immature bovine model. Spine (Phila Pa 1976). 2002;27(7):689-693.

114. Guille JT, D’Andrea LP, Betz RR. Fusionless treatment of scoliosis. Orthop Clin North Am. 2007;38(4):541-545, vii.

115. Newton PO, Upasani VV, Farnsworth CL, et al. Spinal growth modulation with use of a tether in an immature porcine model. J Bone Joint Surg Am. 2008;90(12):2695-2706.

116. Crawford $\mathrm{CH}$, Lenke LG. Growth modulation by means of anterior tethering resulting in progressive correction of juvenile idiopathic scoliosis: a case report. J Bone Joint Surg Am. 2010;92(1): 202-209.
Orthopedic Research and Reviews

\section{Publish your work in this journal}

Orthopedic Research and Reviews is an international, peer-reviewed, open access journal focusing on the patho-physiology of the musculoskeletal system, trauma, surgery and other corrective interventions to restore mobility and function. Advances in new technologies, materials, techniques and pharmacological agents are particularly welcome. The journal welcomes Submit your manuscript here: http://www.dovepress.com/orthopedic-research-and-reviews-journal

\section{Dovepress}

original research, clinical studies, reviews \& evaluations, expert opinion and commentary, case reports and extended reports. The manuscript management system is completely online and includes a very quick and fair peer-review system, which is all easy to use. Visit http://www.dovepress. com/testimonials.php to read real quotes from published authors. 